\title{
PERCEPÇÃO AMBIENTAL DOS CIDADÃOS SOBRE A ARBORIZAÇÃO DE RUAS COM Copernicia prunifera EM NATAL E PARNAMIRIM, RN
}

\author{
ENVIRONMENTAL PERCEPTION OF CITIZENS ABOUT THE USE OF Copernicia \\ prunifera IN URBAN STREETS OF NATAL AND PARNAMIRIM, RN
}

Eduarda Ximenes ${ }^{1}$, Daniela Biondi², Antonio Carlos Batista ${ }^{3}$

\begin{abstract}
RESUMO
A percepção ambiental é uma ferramenta de estudo utilizada para compreender as relações entre a sociedade e a floresta no meio urbano. O objetivo deste trabalho foi verificar a percepção ambiental da comunidade local acerca da arborização de ruas com Copernicia prunifera em Natal e Parnamirim, Rio Grande do Norte. Foram realizadas 345 entrevistas com perguntas abertas em quatro bairros de Natal (Petrópolis, Lagoa Nova, Neópolis e Capim Macio) e um de Parnamirim (Distrito Litoral de Pium e Cotovelo). As perguntas abordaram o caráter socioeconômico e a opinião das pessoas quanto à floresta urbana, incluindo o interesse acerca da arborização de ruas com $C$. prunifera. Verificou-se que os respondentes apreciam o plantio de $C$. prunifera na área urbana e compreendem que os indivíduos arbóreos estão vinculados à maximização do fornecimento dos serviços ecossistêmicos. Assim, a integração da comunidade local com a floresta urbana apresenta-se como uma alternativa viável para a fortalecer a gestão dos espaços públicos e atuar na conservação destes indivíduos.
\end{abstract}

Palavras-chave: Arecaceae; Carnaúba; Educação ambiental; Floresta urbana; Formulário socioambiental.

\begin{abstract}
The study of environmental perception is a tool used to understand the relationship between society and forests in the urban context. This study aimed to analyze the environmental perception of the local community about planting Copernicia prunifera in the streets of Natal and Parnamirim, Rio Grande do Norte. A total of 345 open questions interviews were carried out in four districts of Natal (Petrópolis, Lagoa Nova, Neópolis and Capim Macio) and one in Parnamirim (Distrito Litoral of Pium and Cotovelo). The questions explored the socioeconomic characteristics and people's opinions about the urban forest and the planting of $C$. prunifera in the streets. It was verified that respondents appreciate $C$. prunifera planting in urban areas and understand that arboreal individuals are related to maximizing the ecosystem services. Thus, the integration of the local community with the urban forest is a viable alternative to strengthen the management of public spaces and to act in the conservation of these individuals.
\end{abstract}

Keywords: Arecaceae; Carnaúba; Environmental education; Urban forest; Socio-environmental surveys.

Recebido em: 02.12.2019 e aceito em 11.05.2020

1 Engenheira Florestal. Mestra. Formada pela Universidade Federal do Paraná. Curitiba/PR. E-mail: eduardaximenes@live.com

2 Engenheira Florestal. Doutora. Profa. Titular da Universidade Federal do Paraná. Curitiba/PR. Email: dbiondi@ufpr.br

3 Engenheiro Florestal. Doutor. Professor Titular da Universidade Federal do Paraná. Curitiba/PR. E-mail: batistaufpr@ufpr.br 


\section{INTRODUÇÃO}

Toda a cobertura vegetal presente no perímetro urbano é intitulada de floresta urbana, a qual pode ser classificada em diversas tipologias florestais, tais como praças, parques, bosques, jardins, arborização de ruas, entre outros fragmentos (BIONDI, 2015).

As árvores que compõem a floresta urbana são capazes de promover benefícios sociais, ambientais e econômicos para a população (BARRERA; RUBIO; BANZHAF, 2016), além de representarem a porção da natureza mais acessível aos seus habitantes. Entretanto, como o planejamento e a gestão dos espaços públicos urbanos são competências quase que exclusivas dos órgãos governamentais, a reduzida participação social nesses instrumentos de gestão promove o distanciamento entre as pessoas e o meio ambiente (EMER; CORONA, 2013).

Segundo Viana (2013), as pesquisas sobre percepção ambiental permitem conhecer as preferências da comunidade local quanto à seleção de espécies vegetais que serão introduzidas no espaço urbano, tornando-se tão relevantes quanto as avaliações quali-quantitativas.

Além disso, Silva e Perelló (2010) evidenciam que a presença destas espécies no meio urbano pode aproximar os habitantes da identidade paisagística regional e contribuir com a educação ambiental.

Barros et al. (2018), concordam que é possível identificar o nível de conhecimento das pessoas sobre o tema abordado, contribuindo na orientação de estratégias e políticas públicas ambientais. Emer e Corona (2013), por sua vez, acreditam no desenvolvimento de uma relação positiva entre a floresta urbana e a comunidade, devido o contato com a vegetação urbana despertar um senso de responsabilidade e cuidado pelo patrimônio arbóreo.

Todavia, o sucesso da floresta no meio urbano não se deve exclusivamente à essa relação favorável. Os órgãos responsáveis pela composição do ambiente arbóreo nas cidades possuem o papel de direcionar a seleção de indivíduos que sejam compatíveis tanto com as condições climáticas locais e a atual situação dos espaços destinados a estes indivíduos (canteiros, passeios etc.), quanto à preferência dos moradores e comerciantes da região (BAE, 2011).

Neste sentido, o uso de espécies nativas regionais na arborização de ruas torna-se primordial, visto que estas possuem maiores chances de aclimatação do que as exóticas (WANDERLEY et al., 2018).

Dentre as espécies nativas do semiárido nordestino, destaca-se Copernicia prunifera (Miller) H. E. Moore (carnaúba), com predomínio nos Estados do Ceará, Piauí e Rio Grande do Norte (LEITMAN et al., 2019).

Em seu habitat natural, $C$. prunifera se desenvolve em solos argilosos e áreas alagáveis próximas às margens dos rios (NOGUEIRA, 2009), alcançando entre 15 e $20 \mathrm{~m}$ de altura e, 15 a $25 \mathrm{~cm}$ de diâmetro à altura do peito (DAP) (LORENZI et al., 2004). 
C. prunifera foi introduzida na arborização de ruas de Natal e Parnamirim, RN, por meio do órgão estadual competente a fim de agregar valor paisagístico às cidades. No entanto, os plantios desta espécie foram realizados em áreas públicas residenciais sem levar em consideração um estudo prévio sobre a preferência da comunidade local. Portanto, o objetivo deste trabalho foi verificar a percepção ambiental da comunidade local acerca da arborização de ruas com Copernicia prunifera em Natal e Parnamirim, Rio Grande do Norte.

\section{MATERIAL E MÉTODOS}

A área de estudo abrange os municípios de Natal e Parnamirim, situados na Zona Litoral

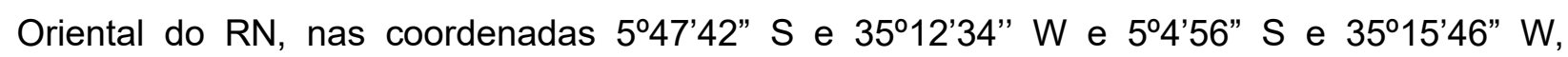
respectivamente (INSTITUTO DE DESENVOLVIMENTO SUSTENTÁVEL E MEIO AMBIENTE DO RIO GRANDE DO NORTE (IDEMA), 2018).

Para verificar a percepção ambiental dos residentes e comerciantes, foi realizada uma pesquisa do tipo Survey (por meio de entrevistas com perguntas abertas) entre os dias 07 e 14 de março de 2019, em quatro bairros de Natal (Petrópolis, Lagoa Nova, Neópolis e Capim Macio) e no de Parnamirim (Distrito Litoral de Pium e Cotovelo), onde cada bairro corresponde a um agrupamento de $C$. prunifera.

A pesquisa só foi iniciada mediante uma consulta e deliberação prévia do Comitê de Ética em Pesquisa em Seres Humanos da Universidade Federal do Paraná (CEP/SD), em cumprimento de todas as resoluções do Conselho Nacional de Saúde (CNS) e normas da Comissão Nacional de Ética em Pesquisa (CONEP). A concessão da pesquisa tem registro do Parecer CEP/SD-PB no 3522512 aprovado na Plataforma Brasil (PB).

Para cada participante, foram explicados os objetivos da pesquisa, sendo solicitada a assinatura do Termo de Consentimento Livre e Esclarecido (TCLE) e, em seguida, realizadas as perguntas do formulário.

As entrevistas abordaram perguntas de caráter socioeconômico (gênero, idade, naturalidade, profissão, grau de escolaridade, renda familiar etc.) e sobre a percepção ambiental da floresta urbana, incluindo principalmente, o interesse da comunidade acerca de $C$. prunifera na arborização dos bairros e buscando compreender se a comunidade percebia a função ecológica, socioeconômica, cultural e paisagística da espécies (Figura 1).

Foram utilizadas imagens de apoio para identificar a preferência das pessoas em relação aos ambientes com ausência de arborização, arborizados com árvores e arborizados com palmeiras e quanto ao uso de C. prunifera na arborização de ruas. 


\section{UNIVERSIDADE FEDERAL DO PARANÁ}

SETOR DE CIÊNCIAS AGRÁRIAS

PROGRAMA DE PÓS-GRADUAÇÃO EM ENGENHARIA FLORESTAL

\section{PESQUISA: PERCEPÇÃO AMBIENTAL DAS PESSOAS EM RELAÇão A CARNAÚBA NA ARBORIZAÇÃO DE RUAS DE NATAL E PARNAMIRIM - RN}

\section{Perfil dos entrevistados}

Gênero: Idade: Naturalidade: Bairro:

Há quanto tempo reside neste local? Em qual bairro/cidade morava anteriormente?

Com que frequência você caminha pelo bairro?

口Todos os dias $\square$ 2-3x na semana $\square$ Apenas para o trabalho/escola $\square$ Apenas para prática de esportes

$\square$ Raramente $\square$ Nunca

A sua residência possui alguma árvore/palmeira?

QNão पSim -Onde? QJardim QQuintal QHorta

\section{Perfil socioeconômico}

Grau de escolaridade: $\square$ Não alfabetizado $\quad \square 19$ grau incompleto $\square 19 \mathrm{gr}$ completo

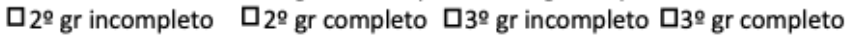

Profissão:

Quantas pessoas moram com você?

Renda familiar: पSem renda; $\square 1$ salário min.; $\square 2$ a 4; $\square 5$ a 10; प10 a 15; पAcima de 15

\section{Percepção ambiental}
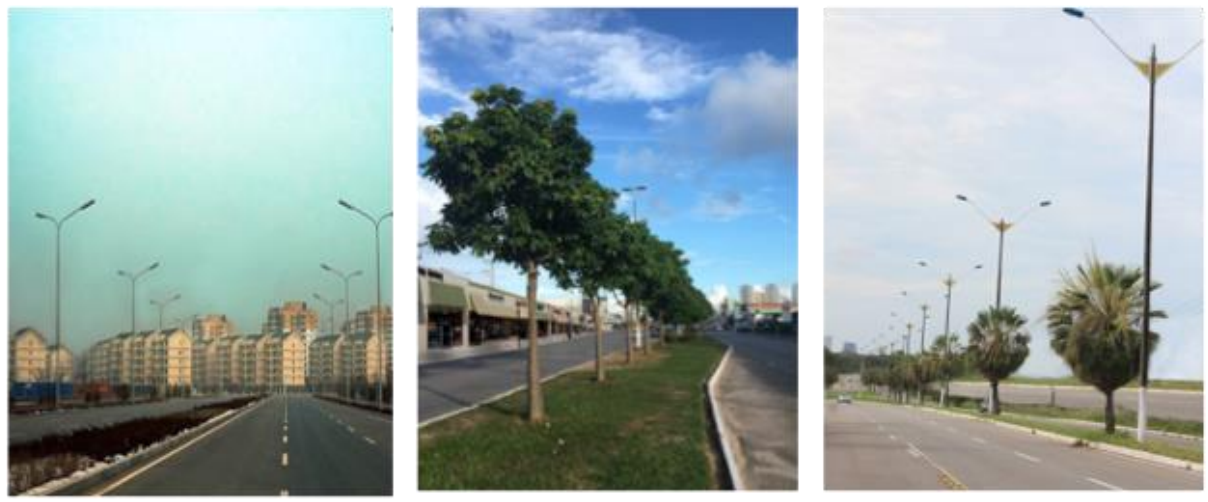

3.1 Você consegue me dizer a diferença entre as fotos acima?

प Não पSim, apenas entre sem vegetação e com vegetação

$\checkmark$ Sim, inclusive entre árvore e palmeira

3.2 Levando em consideração as paisagens acima, em qual desses ambientes você gostaria de morar? Por quê?

3.3 Gosta de árvores? $\square$ Não $\square$ Sim Gosta de palmeiras? प Não $\square$ Sim

\subsection{Você já ouviu falar ou conhece a palmeira carnaúba? प Não प Sim}

3.5 Você conseguiria reconhecer qual dessas palmeiras é a carnaúba?
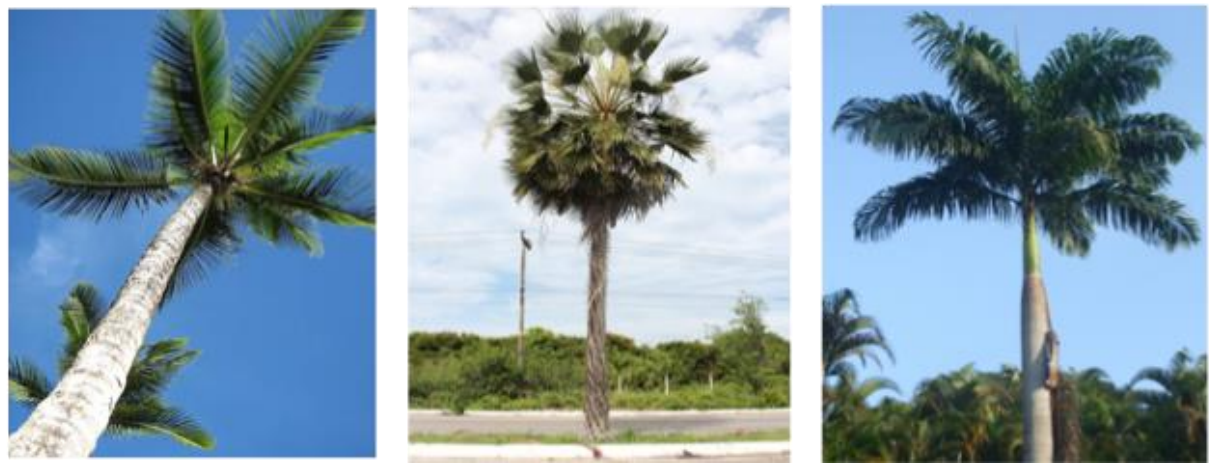
...continuação

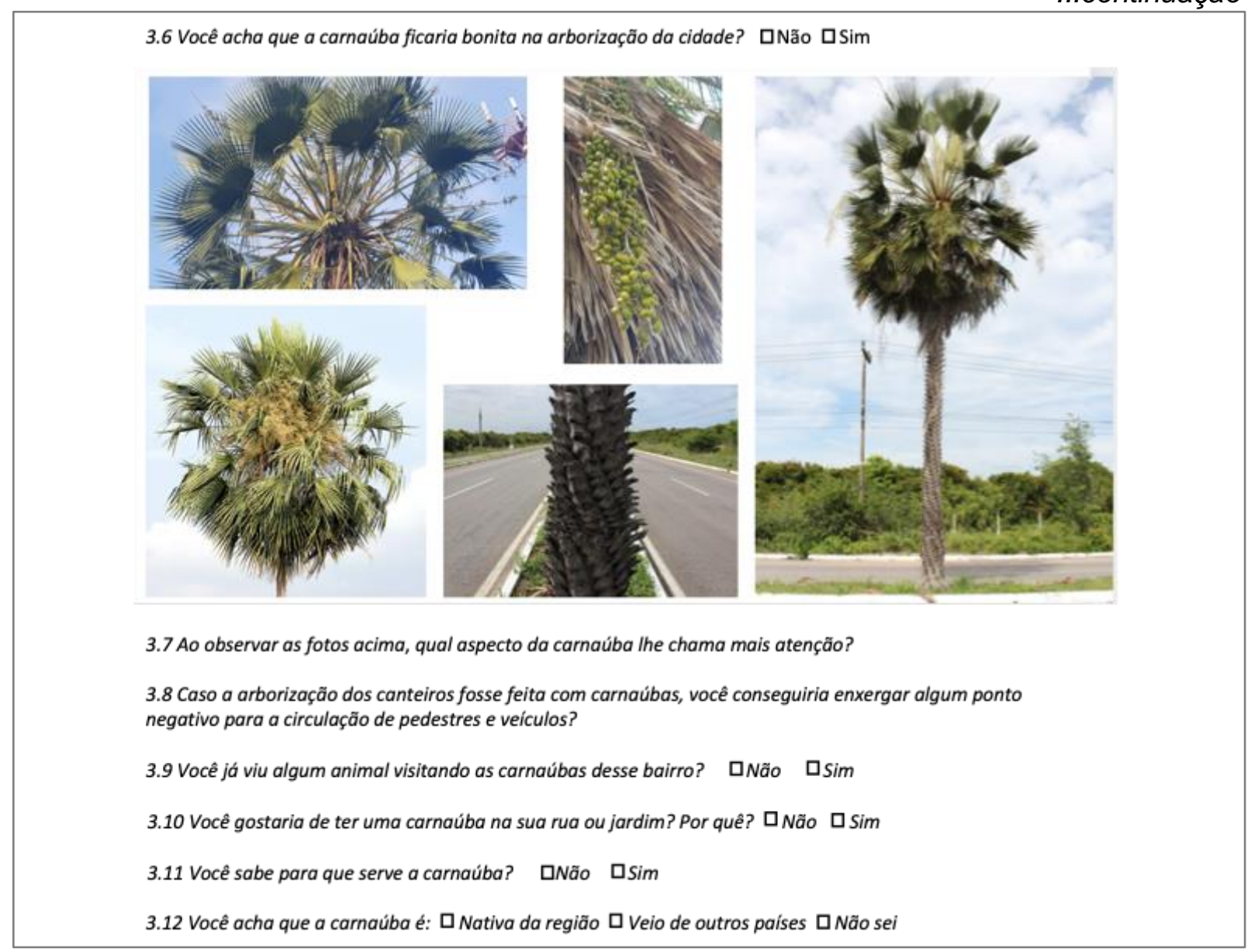

Figura 1. Formulário de percepção ambiental

Fonte: Os autores (2020)

Figure 1. Environmental perception form

As entrevistas foram realizadas apenas com os cidadãos que estavam próximos dos agrupamentos de $C$. prunifera, em um raio de até $100 \mathrm{~m}$. A escolha desta distância deveu-se à maior probabilidade de contato (direto ou indireto) dessas pessoas com o objeto de estudo.

Assim, 69 pessoas foram entrevistadas, em cada um dos cinco agrupamentos de $C$. prunifera, resultando em 345 entrevistas destinadas tanto aos residentes quanto aos comerciantes e trabalhadores dos bairros do entorno.

Após a aplicação dos formulários, os dados obtidos foram plotados em planilhas eletrônicas do Microsoft Office Excel 2013, onde foram definidas categorias para cada grupo de respostas, a fim de classificar e agrupar os conteúdos similares dos entrevistados em cada questão.

A partir da justificativa dos entrevistados quanto às preferências entre ambientes arborizados com árvores e palmeiras, foram estabelecidos os seguintes grupos: a) benefícios da natureza para as pessoas, os quais incluem o bem-estar, controle da poluição atmosférica e sonora e a melhoria microclimática e estética; b) aspectos físicos, incluindo a facilidade de 
manutenção da floresta urbana, familiaridade com o local em que a espécie está inserida, e a não interferência na visibilidade dos motoristas; c) outros, contendo os aspectos citados com menor frequência, como o estímulo a prática de esporte, aspectos sentimentais e preservação da natureza. As pessoas que não utilizaram justificativas plausíveis para a escolha do ambiente foram agrupadas em "sem justificativa".

Por fim, foi criado o grupo para as respostas relacionadas aos cuidados básicos com as plantas, sendo eles: a) serviços prestados pelas órgãos públicos (controle fitossanitário, poda, limpeza de poda e dos canteiros, proteção de mudas contra vandalismo); b) serviços essenciais para a planta (água, adubo e luz solar); e c) não soube responder, para as pessoas que não entenderam ou não quiseram opinar.

\section{RESULTADOS E DISCUSSÃO}

\section{Perfil socioeconômico}

De acordo com os dados coletados, verificou-se predominância do gênero feminino nas respostas (65,61\%), enquanto o gênero masculino representou 34,39\% (Figura 2). Souza (2008), em pesquisa de percepção ambiental em Natal/RN, comenta que a menor participação do público masculino pode estar vinculada à insegurança ou desinformação em responder perguntas de aspectos sociais e ambientais do bairro devido ao pouco tempo em que permanecem em casa.

\section{Gênero}

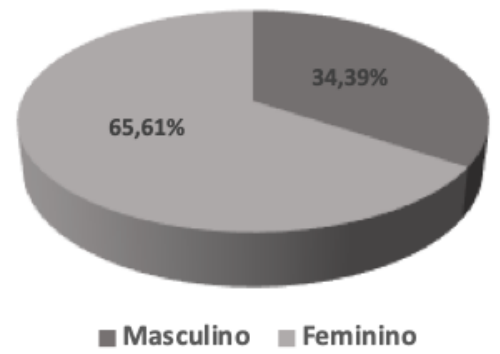

Faixa etária

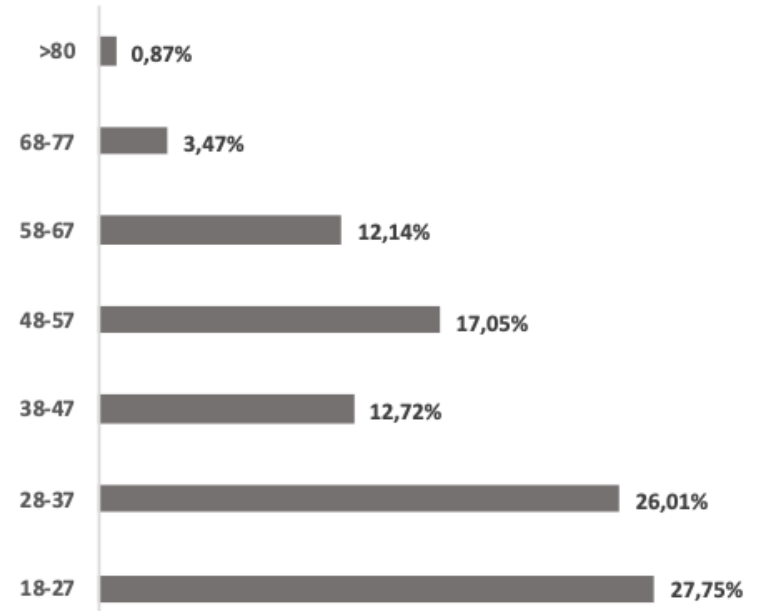

Fonte: Os autores (2020)

Figura 2. Perfil dos entrevistados de Natal e Parnamirim quanto ao gênero e faixa etária

Figure 2. Profile of Natal and Parnamirim respondents regarding gender and age group 
A faixa etária dos entrevistados ficou entre 18 e 80 anos, sendo as classes mais representativas as de 18 a $27(27,75 \%)$ e 28 a 37 (26,01\%) (Figura 2). Segundo o Instituto Brasileiro de Geografia e Estatística ((IBGE), 2010), as faixas etárias de 20 a 24 anos são as que melhor caracterizam a população de Parnamirim e Natal, com 10,2\% da população de cada cidade, seguida da classe de 25 a 29 anos, com 10,1\% e 9,8\% da população, respectivamente. Isto indica que a quantidade de pessoas entrevistadas abrangeu as classes de idade mais populosas das duas cidades.

Dentre os 345 respondentes, 295 (86,13\%) relataram ter nascido no Estado do Rio Grande do Norte, enquanto os demais se distribuíram entre os Estados do Centro-Oeste, Norte, Nordeste, Sul e Sudeste, demonstrando que embora haja uma representação por Estados, esta não é expressiva, pois compreende valores entre 0,29 e 2,60\%.

Quanto às regiões administrativas em que eles residem, a maior parte dos entrevistados afirmou morar na Zona Leste $(31,50 \%)$ e na Zona Sul $(31,21 \%)$ de Natal, onde $40,46 \%$ estão majoritariamente estabelecidos entre 1 e 10 anos.

Com relação ao nível de escolaridade dos entrevistados, foi verificado que o ensino superior completo $(53,76 \%)$ apresentou uma maior quantidade de participantes, seguido do ensino médio completo (25,72\%) e ensino superior incompleto (11,27\%) (Figura 3). Constantin et al. (2019) e Meyer (2015) reforçam que os níveis mais altos de escolaridade refletem positivamente no processo de percepção ambiental.
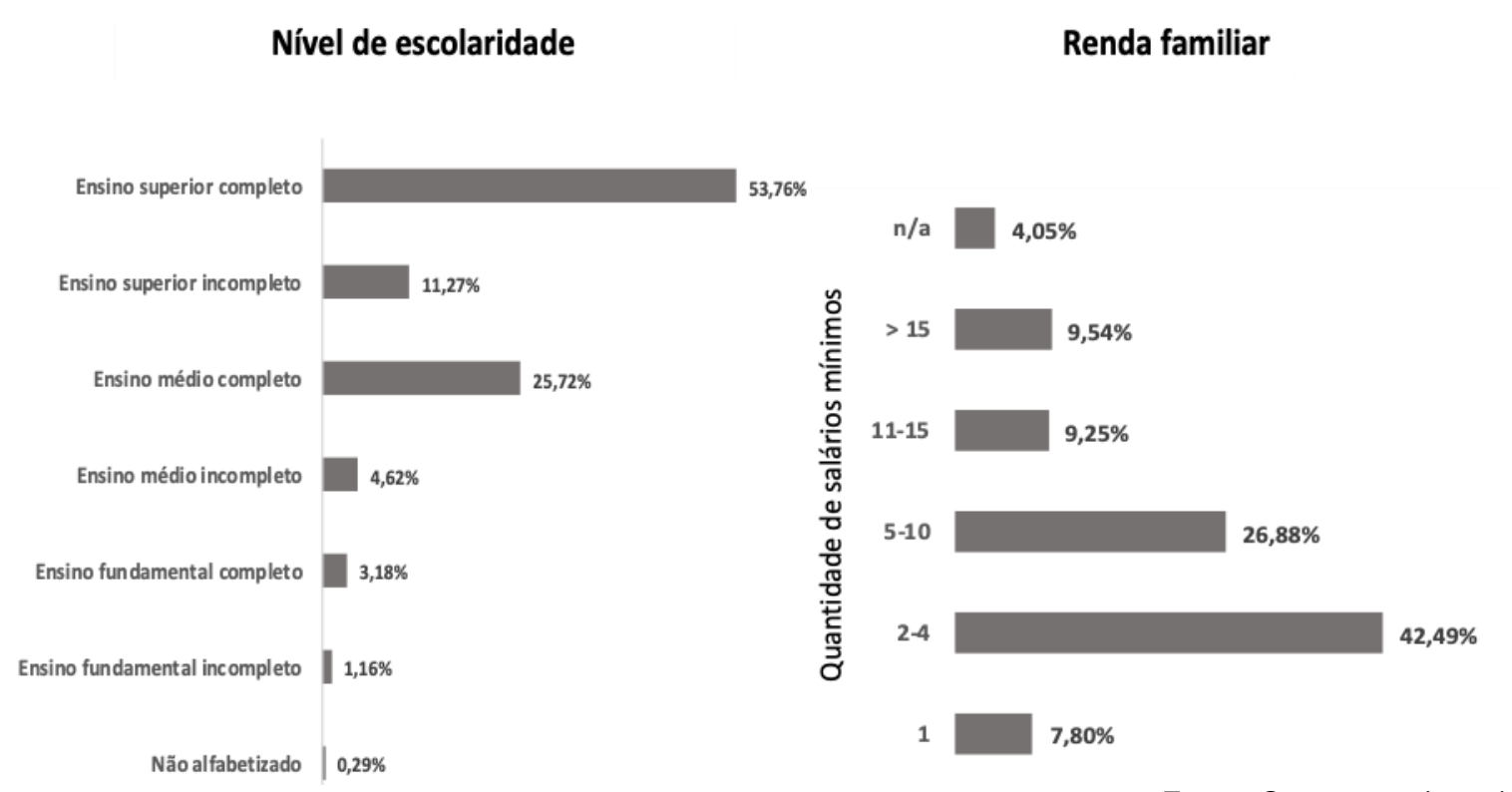

Fonte: Os autores (2020)

Figure 3. Perfil socioeconômico dos entrevistados de Natal e Parnamirim quanto ao grau de escolaridade Figure 3. Socioeconomic profile of Natal and Parnamirim respondents regarding educational level 
Quanto à renda familiar mensal dos respondentes, a maioria recebe entre 2 e 4 salários (42,49\%); 5 a 10 (26,88\%), mais que 15 salários mínimos (9,54\%), 10 a 15 (9,25\%), 1 (7,8\%) e por fim, pessoas que não quiseram expor a sua renda mensal (4,05\%) (Figura 3). Tais dados nos permitem refletir sobre a importância de compreender a percepção ambiental das pessoas sobre a arborização em diferentes núcleos sociais.

\section{Percepção ambiental}

Ao serem questionados sobre as principais diferenças quanto à vegetação nas fotografias utilizadas no material de apoio (Figura 1), aproximadamente $65 \%$ dos entrevistados conseguiram distinguir facilmente árvores de palmeiras (Figura 4), demonstrando o conhecimento sobre os tipos de vegetação.

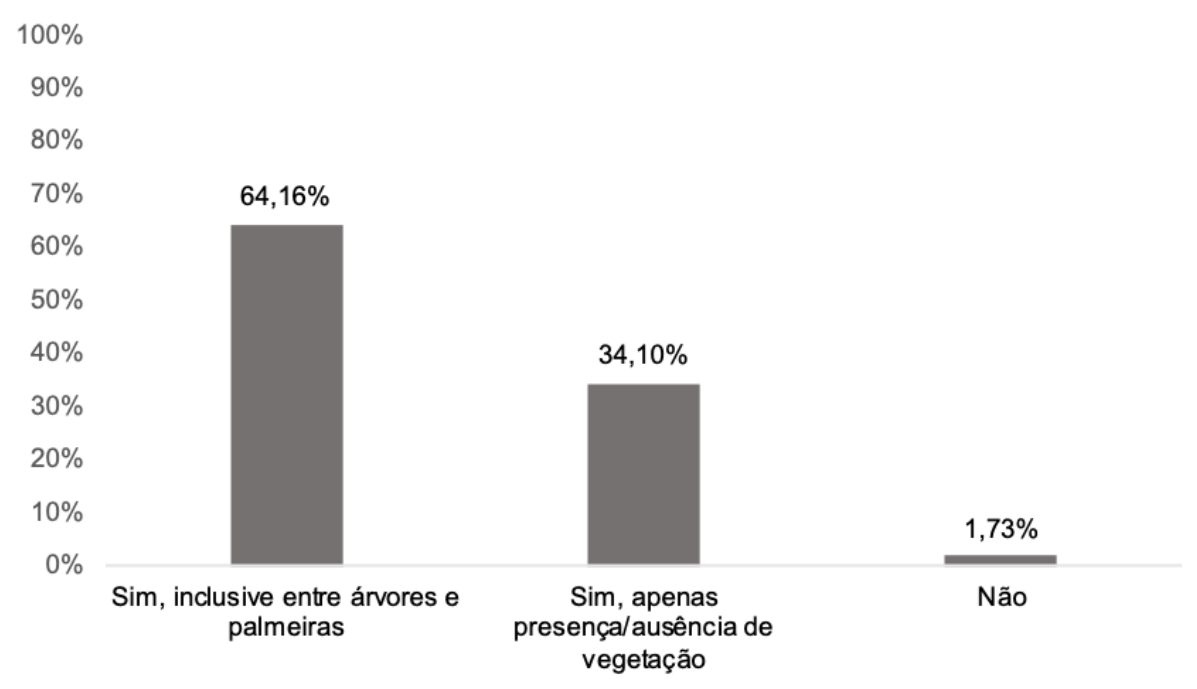

Figura 4. Tipologias vegetais (árvore e palmeira) reconhecidas pelos entrevistados Figure 4. Plants typologies (tree and palm tree) recognized by respondents

No geral, os entrevistados possuíam uma opinião positiva tanto em relação à presença de árvores (96,24\%), quanto à de palmeiras (93,64\%), corroborando com o resultado encontrado por Souza (2008), em que 97\% dos entrevistados afirmaram gostar de indivíduos de porte arbóreo.

A preferência dos respondentes quanto ao tipo de ambiente em que eles gostariam de morar (local sem arborização, arborizado com árvores ou arborizados com palmeiras) (Figura 1), demonstrou que $64,74 \%$ das pessoas preferiam locais arborizados com árvores, enquanto $34,39 \%$ optaram por ambientes arborizados com palmeiras (Figura 5).

É importante frisar que nenhum dos entrevistados optou por residir em locais ausentes de vegetação (Figura 5), entretanto três pessoas $(0,87 \%)$ não demonstraram afeição quanto à 
presença de árvores ou palmeiras, sendo classificadas como "nenhuma das alternativas". Isto demonstra a sensibilização das pessoas quanto aos benefícios que a vegetação proporciona, pois muitos enfatizaram que a temperatura da cidade aumentaria com a ausência de indivíduos de porte arbóreo. Este fato pode ser explicado devido a localização geográfica dos municípios de Natal e Parnamirim, os quais estão inseridos em regiões quentes e úmidas, onde a ausência de indivíduos de porte arbóreo intensifica a sensação de calor.

Dentre os participantes que escolheram os ambientes arborizados com árvores $(64,74 \%)$ (Figura 5), a melhoria microclimática (26,79\%) foi a principal justificativa entre as respostas, onde as pessoas utilizaram termos como "redução da temperatura local", "sombra" e "ventilação", como os principais benefícios (Figura 6).

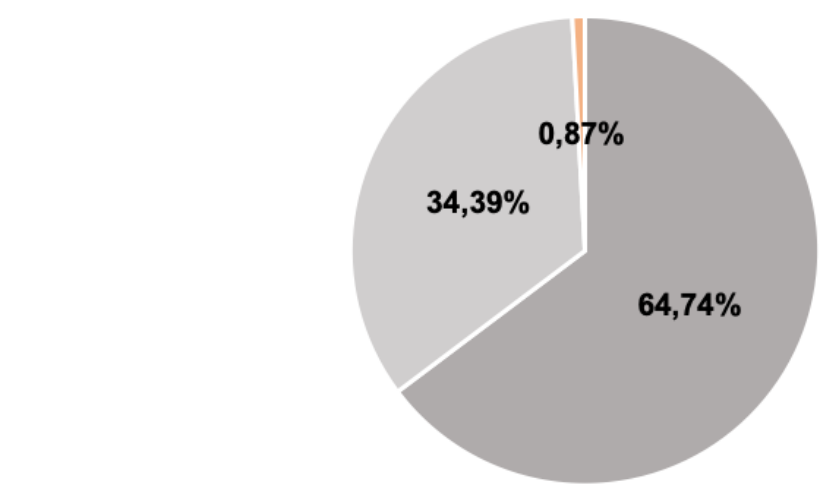

- Arborização com árvores " Arborização com palmeiras " Nenhuma das alternativas

Fonte: Os autores (2020)

Figura 5. Preferências dos respondentes acerca da vegetação utilizada na arborização de ruas Figure 5. Respondents preferences about vegetation used in urban streets

Resultados semelhantes a esta pesquisa foram encontrados por Lacerda et al. (2010) na cidade de São José de Piranhas (PB), onde 66\% dos entrevistados citaram o sombreamento e $32 \%$ a redução do calor como as principais vantagens das árvores.

Em geral, os aspectos físicos (facilidade de manutenção da floresta urbana, familiaridade com o local em que a espécie está inserida e a não interferência na visibilidade dos motoristas) representaram $12,55 \%$ da opinião dos entrevistados, enquanto os aspectos relacionados aos benefícios da natureza para as pessoas (bem-estar, controle da poluição atmosférica e sonora, melhoria microclimática e estética) compreendem 69\% (Figura 6). Este resultado indica que as pessoas estão conscientes das vantagens da presença de árvores nas cidades. 


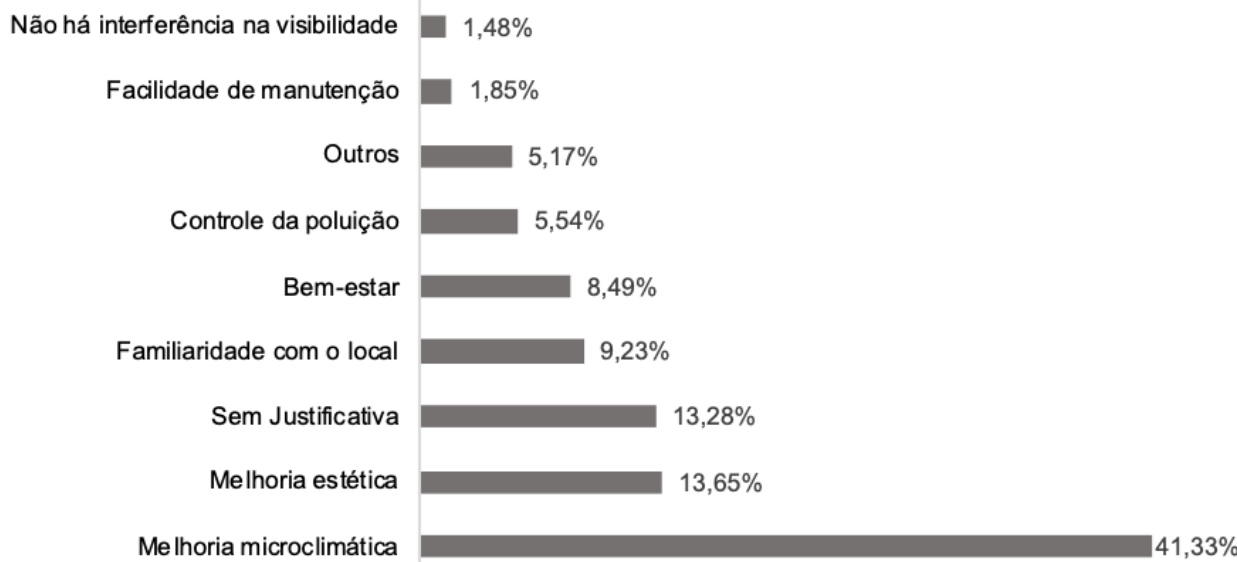

Fonte: Os autores (2020)

Figura 6. Principais justificativas dos participantes de Natal e Parnamirim quanto à preferência por árvores na arborização de ruas

Figure 6. Most important justifications of Natal and Parnamirim participants about the preference for trees in the urban environment

Já a escolha por ambientes arborizados com palmeiras (34,39\%) (Figura 5), a melhoria estética (22,22\%) foi a justificativa que atingiu a maior marca percentual (Figura 7). De acordo com Barros, Guimarães e Carvalho (2010), as palmeiras são largamente utilizadas na composição do paisagismo nacional devido a sua beleza exuberante.

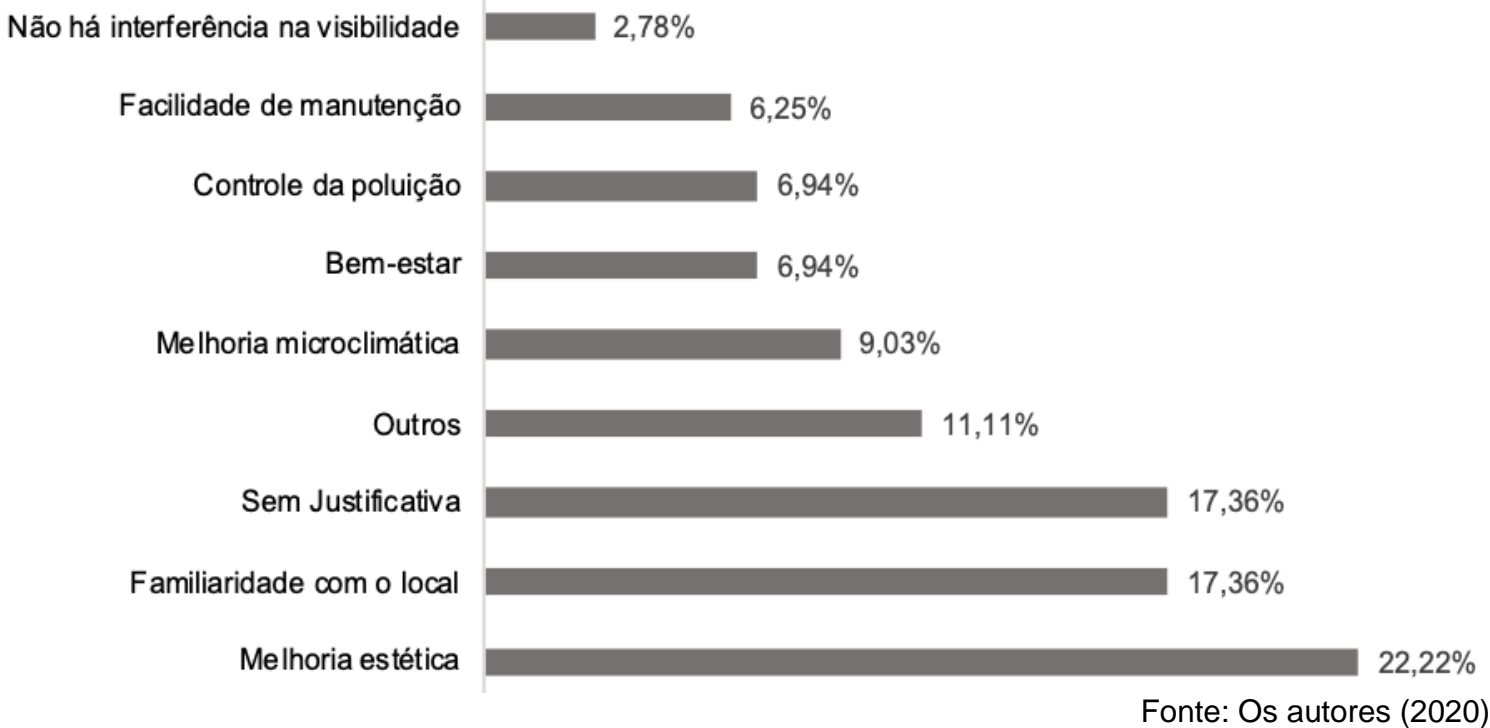

Figura 7. Principais justificativas dos participantes de Natal e Parnamirim quanto à preferência por palmeiras na arborização de ruas

Figure 7. Most important justifications of Natal and Parnamirim participants about the preference for palm trees in the urban environment

Além da estética, outros aspectos relacionados aos benefícios da natureza para as pessoas foram citados, tais como: melhoria microclimática $(9,03 \%)$, bem-estar $(6,94 \%)$ e controle da poluição atmosférica (6,94\%). Entretanto, esta somatória representa 22,91\% das justificativas dos participantes. Assim, é possível observar que há uma tendência da população em relacionar 
a presença de palmeiras no meio urbano como algo exclusivamente paisagístico, como se não houvesse outros benefícios além do estético.

Ribeiro (2018), ao realizar estudos sobre o conforto térmico proporcionado por palmeiras, evidenciou resultados satisfatórios no que diz respeito às espécies com maiores áreas foliares favorecerem significativamente o microclima de cidades tropicais. $O$ autor afirma que espécies como washingtônia (Washingtonia robusta $H$. Wendl) e rabo-de-raposa (Wodyetia bifurcata Irvine) são capazes de reduzir até 77,85 e $61 \%$ da atenuação da radiação solar, respectivamente. Além disso, o autor evidencia que o potencial de arrefecimento aumenta quando as palmeiras são plantadas de forma agrupada, onde encontraram $85,35 \%$ da redução da temperatura para sete indivíduos de livistona (Livistona saribus (Loureiro) Merril ex. A. Chevalier).

Em relação à resposta dos participantes quanto à existência de algum ponto negativo para a circulação de pedestres e veículos em canteiros arborizados com C. prunifera, 73,70\% não identificaram possíveis problemas. Entretanto, 24,86\% dos entrevistados (97 pessoas) acreditam que existem pontos negativos quanto à sua implantação em canteiros e 1,45\% não soube responder. Dentre estes, os principais problemas citados foram a redução do conforto térmico $(30,93 \%)$, a queda das folhas $(25,77 \%)$ devido ao entupimento dos bueiros e possível risco de acidentes com carros e pedestres, a presença de espinhos $(21,65 \%)$ no estipe e nas folhas (Figura 8).

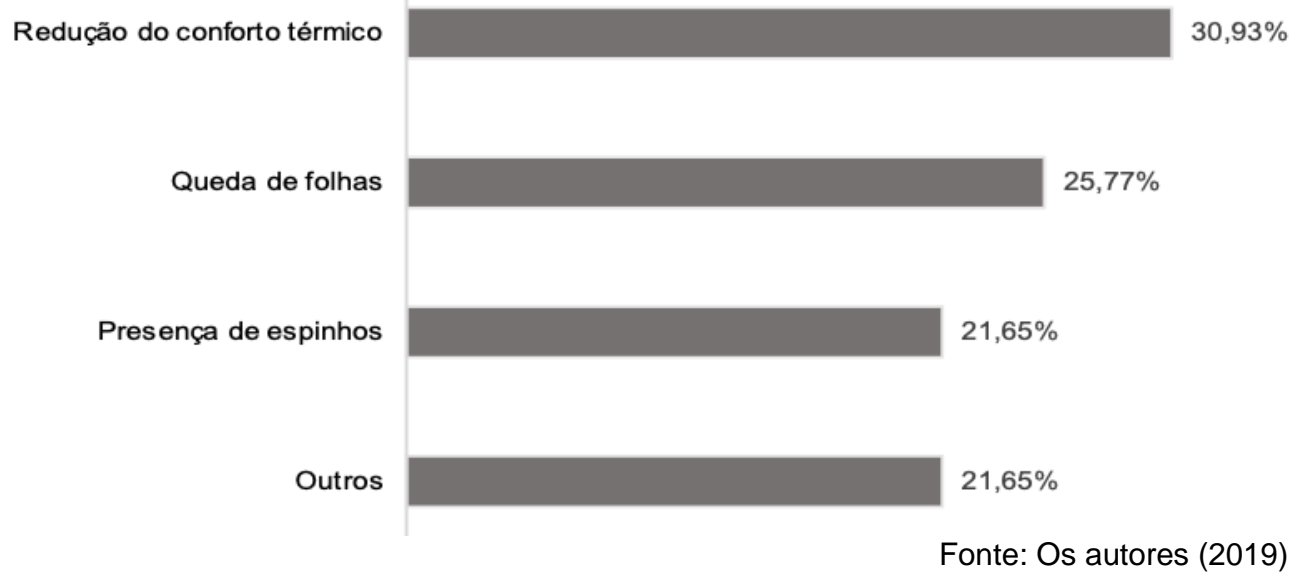

Figura 8. Percepção dos entrevistados de Natal e Parnamirim quanto aos possíveis problemas com a arborização de canteiros com $C$. prunifera

Figure 8. Perception of respondents of Natal e Parnamirim about the possible problems with the use of $C$. prunifera in street

A categoria outros $(21,65 \%)$ que representou os problemas citados em menores quantidades (Figura 8), tais como o acúmulo de insetos e presença de cupim no estipe, a queda de frutos, o risco de queda da palmeira, o comprometimento da visibilidade dos motoristas e do 
deslocamento dos pedestres, o conflito com a fiação elétrica e a dificuldade de manutenção dos órgãos competentes.

Embora $24,86 \%$ dos respondentes acreditem que existam problemas na utilização de $C$. prunifera no meio urbano, a pesquisa realizada por Lacerda, Lira Filho e Santos (2011), averiguou que a espécie possui potencial para ser introduzida na arborização de ruas e áreas verdes devido as suas características estruturais e morfológicas, como o seu porte médio, a floração contínua e de tamanho reduzido e a presença de frutos pequenos e carnosos.

Martini (2011) aborda a importância de se conhecer as épocas do ano com maior incidência de queda de frutos, flores e folhas a fim de aumentar a quantidade de agentes de limpeza nas cidades e reduzir os problemas com entupimentos de bueiro. Pereira e Tonini (2012), por sua vez, atentam para definição de estratégias sustentáveis de uso da espécie.

No caso de $C$. prunifera, as enormes folhas palmadas e arredondadas podem dificultar o escoamento de água e causar alagamento nas vias públicas, entretanto se a gestão municipal tiver conhecimento das épocas de desfolhamento da espécie e atuar em conjunto com as comunidades tradicionais, as folhas provenientes das podas podem ser direcionadas às artesãs locais, contribuindo de forma social e econômica com o desenvolvimento da cidade e das pessoas.

\section{CONCLUSÕES}

Os entrevistados demonstraram apreciar o plantio de C. prunifera nas ruas das cidades avaliadas, embora ainda prefiram a presença de árvores, justificando que estas promovem uma melhoria microclimática maior, enquanto as palmeiras contribuem com a beleza cênica.

Neste sentido, a maioria das pessoas entrevistadas não relatou aspectos negativos quanto à implantação da espécie estudada na arborização de ruas, além de manifestarem conhecimento suficiente sobre a espécie. Assim, a integração da comunidade local com a floresta urbana apresenta-se como uma alternativa viável para fortalecer a gestão dos espaços públicos e atuar na conservação destes indivíduos.

Por fim, foi possível verificar que os respondentes apreciam indivíduos de porte arbóreo na área urbana e compreendem que a sua presença está vinculada à maximização do fornecimento dos serviços ecossistêmicos.

\section{AGRADECIMENTOS}

Ao Conselho Nacional de Desenvolvimento Científico e Tecnológico (CNPQ) pela concessão das bolsas de estudo para a realização desta pesquisa e ao Programa de Pós- 
graduação em Engenharia Florestal (PPGEF) da Universidade Federal do Paraná (UFPR) pela oportunidade concedida.

\section{REFERÊNCIAS}

BAE, $H$. Urban stream restoration in Korea: design considerations and residents' willingness to pay. Urban Forestry and Urban Greening, Davis, v. 10, n. 1, p. 119-126, 2011.

BARRERA, F.; RUBIO, P.; BANZHAF, E. The value of vegetation cover for ecosystem services in the suburban context. Urban Forestry and Urban Greening, Davis, v. 16, n. 1, p. 110-122, 2016.

BARROS, E. F. S.; GUIMARÃES, G. F. A.; CARVALHO, R. S. Arborização urbana em quadras de diferentes padrões construtivos na cidade de Jataí. Revista Árvore, Viçosa, v. 2, n. 34. p. 287-295, 2010.

BARROS, V. S.; MARTINS, C. M.; SANTOS, M. A. S.; REBELLO, F. K.; MONTEIRO, C. W. B.; MESQUITA, I. S. B. Avaliação da organização árborea e a percepção dos usuários das praças do município de Mocajuba, Estado do Pará, Brasil. Revista da Sociedade Brasileira de Arborização Urbana, Piracicaba, v. 13, n. 3, p. 01-12, 2018.

BIONDI, D. Floresta urbana: conceitos e terminologias. In: BIONDI, D. (Ed). Floresta Urbana. Curitiba: a autora, 2015. p. 11-27.

CONSTANTIN, A. M.; NUNES, D. F.; OLIVEIRA, E. F. P.; JASPER, A. Influência do nível de escolaridade na percepção ambiental da população local sobre o monumento natural das árvores fossilizadas do Tocantins (MNAFTO). Revista Estudo \& Debate, Lajeado, v. 26, n. 2, p. 74-88, 2019.

EMER, A. A.; CORONA, H. M. P. Percepção ambiental: uma ferramenta para discutir o ambiente urbano. ANAP Brasil, Tupã, v. 6, n. 7, p. 105-121, 2013.

INSTITUTO BRASILEIRO DE GEOGRAFIA E ESTATÍSTICA (IBGE). Censo 2010. 2010. Disponível em: <https://censo2010.ibge.gov.br>. Acesso em: 05 jun. 2019.

INSTITUTO DE DESENVOLVIMENTO SUSTENTÁVEL E MEIO AMBIENTE DO RIO GRANDE DO NORTE (IDEMA). Anuário Estatístico do Rio Grande do Norte. 2018. Disponível em: <http://www.idema.rn.gov.br/Conteudo.asp?TRAN=ITEM\&TARG=1357\&ACT=null\&PAGE=0\&P ARM=null\&LBL=Socioeconômicos >. Acesso em: 25 fev. 2020.

LACERDA, N. P.; SOUTO, P. C.; DIAS, R. S.; SOUTO, L. S.; SOUTO, J. S. Percepção dos residentes sobre a arborização da cidade de São José de Piranhas-PB. Revista da Sociedade Brasileira de Arborização Urbana, Piracicaba, v. 5, n. 4, p. 81-95, 2010.

LACERDA, R. M. A.; LIRA FILHO, J. A.; SANTOS, R. V. Indicação de espécies de porte arbóreo para a arborização urbana no semi-árido paraibano. Revista da Sociedade Brasileira de Arborização Urbana, Piracicaba, v. 6, n. 1, p. 51-68, 2011. 
LEITMAN, P.; SOARES, K.; HENDERSON, A.; NOBLICK, L.; et al. Arecaceae na Lista de Espécies da Flora do Brasil. 2019. Disponível em: <http://floradobrasil.jbrj.gov.br/jabot/florado brasil/FB53>. Acesso em: 12 mai. 2019.

LORENZI, H.; SOUZA, H. M.; MEDEIROS-COSTA, J. T.; CERQUEIRA, L. S. C.; FERREIRA, E. Palmeiras brasileiras e exóticas cultivadas. Nova Odessa: Instituto Plantarum de Estudos da Flora, 2004. 416 p.

MARTINI, A. Estudo fenológico em árvores de rua. In: BIONDI, D.; LIMA NETO, E. M. de (Org.). Pesquisas em arborização de ruas. Curitiba, 2011, p. 29-48.

MEYER, A. Does education increase pro-environmental behavior? Evidence from Europe. Ecological Economics, Amsterdan, v. 116, n. 1, p. 108-121, 2015.

NOGUEIRA, D. H. Qualidade e potencial de utilização de frutos de genótipos de carnaubeira (Copernicia prunifera) oriundos do estado do Ceará. 134f. Tese (Doutorado em Agronomia) - Universidade Federal da Paraíba, Areia, 2009.

PEREIRA, M. R. N.; TONINI, H. Fenologia da andiroba (Carapa guianensis, Aubl., MELIACEAE) no sul do estado de Roraima. Ciência Florestal, Santa Maria, v. 22, n. 1, p. 47-58, 2012.

RIBEIRO, N. L. D. S. Atenuação solar e sombreamento produzido por espécies de palmeiras em área urbana. 107f. Dissertação (Mestrado em Arquitetura, Tecnologia e Cidade) - Universidade Estadual de Campinas, Campinas, 2018.

SILVA, J. G.; PERELLÓ, L. F. C. Conservação de espécies ameaçadas do Rio Grande do Sul através de seu uso no paisagismo. Revista da Sociedade Brasileira de Arborização Urbana, Piracicaba, v. 5, n. 4, p. 01-21, 2010.

SOUZA, M. S. Arborização urbana e percepção ambiental: uma análise descritiva de dois bairros de Natal/RN. 99f. Dissertação (Mestrado em Geografia) - Universidade Federal do Rio Grande do Norte, Natal, 2008.

VIANA, S. M. Percepção e quantificação das árvores na área urbana do município de São Carlos-SP. 211f. Tese (Doutorado em Recursos Florestais) - Escola Superior de Piracicaba, 2013.

WANDERLEY, R. J. C.; PEREZ, C. A. M.; RABÊLO, D.; SOUZA, P. A.; GIONGO, M.; SANTOS, A. F. Estudo quali-quantitativo e percepção ambiental da arborização do Setor Jardim Sevilha, Gurupi-TO. Revista da Sociedade Brasileira de Arborização Urbana, Piracicaba, v. 12, n. 4, p. 53-68, 2018. 